\title{
HIF-1 $\alpha$ downregulates miR-17/20a directly targeting p21 and STAT3: a role in myeloid leukemic cell differentiation
}

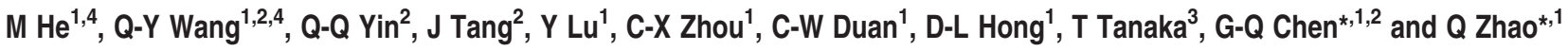

Hypoxia-inducible factor 1 (HIF-1) is a crucial transcription factor for the cellular adaptive response to hypoxia, which contributes to multiple events in cancer biology. MicroRNAs (miRNAs) are involved in almost all cellular activities such as differentiation, proliferation, and apoptosis. In this work, we use miRNA microarrays to profile miRNA expression in acute myeloid leukemia (AML) cells with inducible HIF-1 $\alpha$ expression, and identify 19 differentially expressed miRNAs. Our study shows that HIF-1 $\alpha$ represses the expression of miR-17 and miR-20a by downregulating c-Myc expression. These two miRNAs alleviate hypoxia and HIF-1 $\alpha$-induced differentiation of AML cells. More intriguingly, miR-17 and miR-20a directly inhibit the p21 and STAT3 (signal transducer and activator of transcription 3) expression, both of which can reverse miR-17/miR-20a-mediated abrogation of HIF-1 $\alpha$-induced differentiation. Moreover, we show in vivo that miR-20a contributes to HIF-1 $\alpha$-induced differentiation of leukemic cells. Taken together, our results suggest that HIF-1 $\alpha$ regulates the miRNA network to interfere with AML cell differentiation, representing a novel molecular mechanism for HIF-1-mediated anti-leukemic action.

Cell Death and Differentiation (2013) 20, 408-418; doi:10.1038/cdd.2012.130; published online 12 October 2012

Hypoxia-inducible factor-1 (HIF-1), a heterodimeric transcriptional factor that consists of the oxygen-sensitive alpha subunit (HIF-1 $\alpha)$ and the constitutively expressed beta subunit $(\mathrm{HIF}-1 \beta)$, is a master regulator for the cellular adaptive response to oxygen concentration. ${ }^{1}$ Under normoxic conditions, proline residues 402 and 564 of the HIF- $1 \alpha$ protein are hydroxylated by specific prolyl hydroxylases (PHDs) that utilize $\mathrm{O}_{2}$ and $\alpha$-ketoglutarate as co-factors. The hydroxylated $\mathrm{HIF}-1 \alpha$ protein is subject to ubiquitination by the E3 ubiquitin ligase von Hippel-Lindau (VHL), which leads to its degradation. In contrast, hypoxic conditions cause the accumulation of $\mathrm{HIF}-1 \alpha$ protein by inhibiting its hydroxylation, and subsequent ubiquitination and degradation. ${ }^{2}$ The stabilized HIF- $1 \alpha$ protein translocates into the nucleus, where it forms a heterodimer with $\mathrm{HIF}-1 \beta$ and modulates the expression of hundreds of genes through binding to hypoxia-responsive elements (HREs; 5'-RCGTG-3') on their promoters. These HIF-1targeted genes help the cell adapt to hypoxia by influencing processes such as erythropoiesis, angiogenesis, cell metabolism, growth, apoptosis, and differentiation.

Intriguingly, HIF- $1 \alpha$ has been shown to contribute to the pathogenesis and progression of multiple kinds of diseases, including cancer. ${ }^{1,3}$ Although a hypoxic microenvironment is regarded as a hallmark of solid tumors, and hypoxia-stabilized
HIF-1 $\alpha$ protein contributes to tumor growth, angiogenesis, and metastasis, ${ }^{4}$ several groups, including our own, have reported that $\mathrm{HIF}-1 \alpha$ protein can trigger acute myeloid leukemia $(\mathrm{AML})$ cells to undergo differentiation through a transcription-independent mechanism, inhibiting the progression of AML. ${ }^{5-9}$

MicroRNAs (miRNAs) are a distinct class of small noncoding RNAs of around 22 nucleotides in length that posttranscriptionally repress expression of target genes through imperfect base pairing with the $3^{\prime}$ untranslated region (UTR), leading to the reduced translation and degradation of the mRNA. MiRNAs have been widely associated with the development of major diseases. ${ }^{10}$ More recently, a functional link between HIF-1 and miRNA expression has been documented by some groups. HIF- $1 \alpha$ can be targeted by the miR-17-92 cluster, miR-424 and miR-20b. ${ }^{11-13}$ A specific group of miRNAs have been reported to be induced in response to hypoxia, at least partially via an HIF-1-dependent mechanism. ${ }^{14}$ However, much less is known about possible effects of HIF-1 on the expression of miRNAs, and the role that this regulation may have in $\mathrm{AML}$ cells. Here, we provide the first demonstration that HIF- $1 \alpha$ represses the expression of miR-17 and miR-20a in AML cells through downregulating c-Myc expression. We further show that these two miRNAs

${ }^{1}$ Key Laboratory of Cell Differentiation and Apoptosis of Ministry of Education, Department of Pathophysiology, Shanghai Jiao Tong University School of Medicine (SJTU-SM), Shanghai, China; ${ }^{2}$ Institute of Health Sciences, SJTU-SM \& Shanghai Institutes for Biological Sciences of Chinese Academy of Sciences, Shanghai, China and ${ }^{3}$ School of Pharmacy, Hyogo University of Health Sciences, Kobe, Japan

${ }^{*}$ Corresponding author: G-Q Chen and Q Zhao, Department of Pathophysiology, Shanghai Jiaotong University School of Medicine, No. 280, Chong-Qing South Road, Shanghai, 200025, China. Tel/Fax: +86 21 64154900; E-mail: chengq@ shsmu.edu.cn or qzhao@ shsmu.edu.cn

${ }^{4}$ These authors contributed equally to this work.

Keywords: hypoxia-inducible factor $1 \alpha$ (HIF-1 $\alpha$ ); microRNA; acute myeloid leukemia (AML)

Abbreviations: AML, acute myeloid leukemia; CBMC, cord blood mononuclear cells; CDK, cyclin-dependent kinase; C/EBP $\alpha$, CCAAT/enhancer binding protein alpha; DLBCLs, diffuse large B-cell lymphomas; HIF-1, hypoxia-inducible factor 1; HREs, hypoxia-responsive elements; PHD, prolyl hydroxylase; STAT3, signal transducer and activator of transcription 3; UTR, untranslated region; VEGF, vascular endothelial growth factor; VHL, von Hippel-Lindau

Received 16.1.12; revised 03.9.12; accepted 10.9.12; Edited by B Dynlacht; published online 12.10 .12 
target p21 and STAT3 (signal transducer and activator of transcription 3). Our study shed light on a novel miRNAdependent mechanism through which $\mathrm{HIF}-1 \alpha$ induces differentiation and inhibits proliferation in leukemic cells.

\section{Results}

HIF-1 $\alpha$ regulates the expression of a specific set of miRNAs in AML cells. To investigate how $\mathrm{HIF}-1 \alpha$ regulates the expression of miRNAs in AML cells, we compared miRNA expression profiles between U937T ${ }^{\text {HIF-1 } \alpha}$ and $\mathrm{U} 37 \mathrm{~T}^{\text {empty }}$ cells that we established previously. ${ }^{9}$ In U937T HIF-1 $\alpha$ but not in U937T ${ }^{\text {empty }}$ cells, HIF-1 $\alpha$ protein is induced by tetracycline withdrawal (Figure 1a). We grew both cell types in tetracycline-free medium for different periods of time and analyzed miRNA expression profiles using microarrays. The expression profiles of 19 miRNAs were significantly differentially expressed in the two cell types $(P<0.05)$ (Figure 1b). Out of these 19 miRNAs, 13 were upregulated in U937T HIF-1 $\alpha$ cells on days 2 and 4 in the tetracycline-free medium and 6 were downregulated (Figure 1b). Intriguingly, four out of the six downregulated miRNAs belong to the miR-17-92 cluster. We validated the microarray data using real-time RT-PCR and northern blot analysis (Figures 1c and d; Supplementary Figure S1).

HIF-1 $\alpha$ downregulates miR-17 and miR-20a in AML cell lines. We used bioinformatics analysis to predict the most significant candidate miRNAs. Using miRNA-gene ontology (GO) network, we found that miR-17 and miR-20a were the strongest targets (Supplementary Figure S2, Excel 1). Additionally, miR-17 and miR-20a showed the highest target gene degrees in miRNA-target gene network (Figure 2; Supplementary Excel 2). Thus, we focused on miR-17 and miR-20a in the following experiments. To confirm that HIF-1 $\alpha$ downregulates miR-17 and miR-20a, we incubated U937 cells and another AML cell line, NB4 cells, under hypoxic conditions $\left(1 \% \mathrm{O}_{2}\right)$, which induced HIF-1 $\alpha$ protein accumulation (Supplementary Figures S3A and S4A). More interestingly, hypoxia also decreased the expression of miR-17 and miR-20a in both AML cell lines (Supplementary Figures S3B, C S4B and C). Consistent with previous findings, ${ }^{5,15}$ hypoxia also triggered growth arrest (Supplementary Figures S3D and S4D) and differentiation, as evidenced by the expression of CD11c, a mature myeloid cell surface marker (Supplementary Figures S3E and S4E). Moreover, when HIF-1 $\alpha$ was knocked down in the parental U937 cell line, hypoxia-induced miR-17 and miR-20a downregulation (Supplementary Figures S5A-C) was abrogated, suggesting that $\mathrm{HIF}-1 \alpha$ suppresses $\mathrm{miR}-17$ and miR-20a expression during hypoxia.

HIF-1 $\alpha$ inhibits miR-17 and miR-20a in a transcriptionindependent manner. To determine whether downregulation of miR-17 and miR-20a depends on the transcriptional activity of HIF-1 protein, we transfected shRNA against a

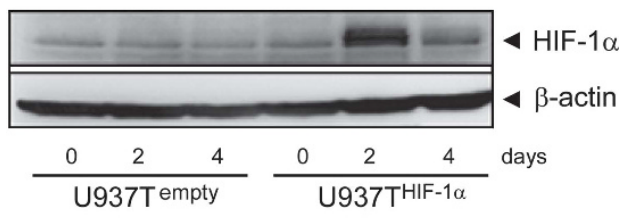

C
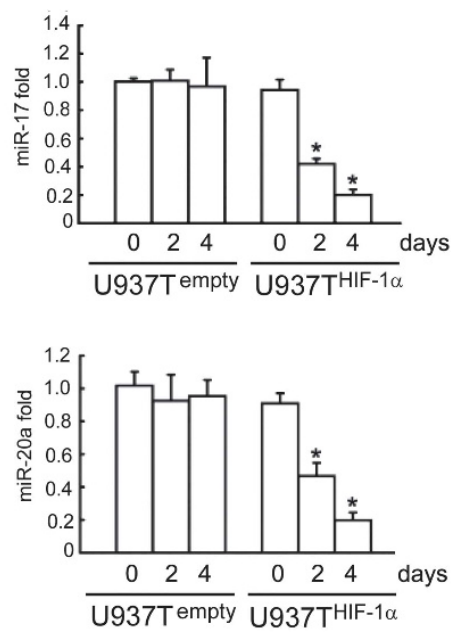

b
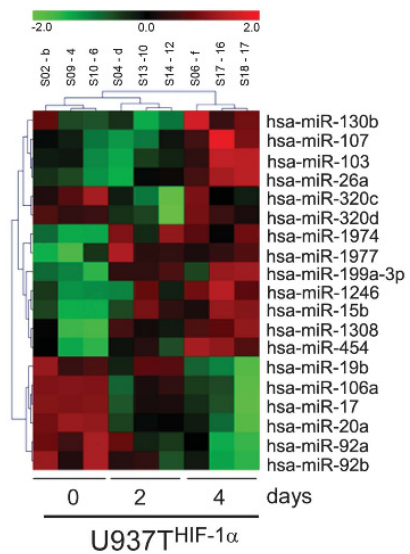

d

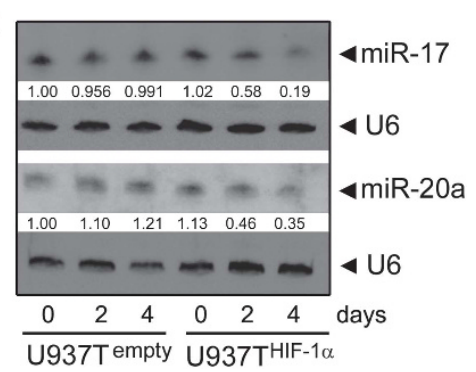

Figure 1 Validation of HIF-1 $\alpha$ regulated miRNA expression profiles in U937 cells. (a) HIF-1 $\alpha$ expression in U937T ${ }^{\text {empty }}$ and U937T ${ }^{\mathrm{HIF}-1 \alpha}$ cells on days 0 , 2, and 4 after tetracycline removal. (b) Heat map of differentially expressed miRNA profiling upon HIF-1 $\alpha$ induction in U937T ${ }^{\text {HIF-1 } \alpha}$ cells. Differential profiling using microarrays included three samples per group and time point. Red indicates upregulated and green shows downregulated miRNAs. The upper number of the map ' -2 to 2 ' represents the $z$-value range, while the labels from S02-b to S18-17 represent sample names of different groups. (c and d) Validation of the downregulated expression of miR-17 or miR-20a by miRNA-specific qRT-PCR (c) and northern blot (d). Triplicate assays were done for each RNA sample and the relative amount of each miRNA was normalized to U6 snRNA. Statistically significant differences among three groups in different time point was indicated by ${ }^{*} P<0.05$ 
HIF-1 $\beta$ into U937 ${ }^{\mathrm{HIF}-1 \alpha}$ cells (named as U937T ${ }^{\mathrm{HIF}-1 \alpha-\operatorname{shR}-\beta 5}$ cells) or a negative control shRNA (named as U937T ${ }^{\mathrm{HIF}-1 \alpha-\mathrm{NC}}$ cells). As depicted in Figure $3 a$, shR- $\beta 5$ significantly silenced expression of HIF-1 $\beta$. Accordingly, it also inhibited the expression of two commonly used HIF-1-targeted genes, vascular endothelial growth factor (VEGF) and Glut-1 in U937T ${ }^{\mathrm{HIF}-1 \alpha-\text { shR- } \beta 5}$ cells (Supplementary Figure S6), confirming the effectiveness of HIF-1 $\beta$ knockdown. However, northern blot and RT-PCR assays showed that HIF-1 $\beta$ knockdown did not affect the downregulation of miR-17 or miR-20a by inducible expression of HIF- $1 \alpha$ (Figures $3 a$ and $b$ ). In line with this notion, knockdown of HIF-1 $\beta$ also failed to affect hypoxia-induced downregulation of miR-17 and miR-20a (Supplementary Figures S7A-C). These results suggest that the HIF-1-induced repression of miR-17 and miR-20a is independent of its transcriptional activity.

HIF-1 $\alpha$ inhibits c-Myc expression via C/EBP $\alpha$. Next, we detected the expression of $c-M y c$ in U937 ${ }^{\mathrm{HIF}-1 \alpha}$ cells, because it was reported that miR-17 or miR-20a could be positively regulated by $\mathrm{c}-\mathrm{Myc}$ in several types of cells including diverse cancer cells. ${ }^{16}$ Interestingly, HIF- $1 \alpha$ protein accumulation after tetracycline withdrawal in U937 $\mathrm{T}^{\mathrm{HIF}-1 \alpha}$ cells also decreased the expression of c-Myc (Figure 3c). Furthermore, RT-PCR showed that c-Myc mRNA was decreased after tetracycline removal (Supplementary Figure S8A), and the loss of c-Myc induced by $\mathrm{HIF}-1 \alpha$ overexpression could not be rescued by treatment with the proteasome inhibitor MG132 (Supplementary Figure S8B) or shRNA against HIF-1 $\beta$ (Supplementary Figures S8C and D), indicating that $\mathrm{HIF}-1 \alpha$ decreases $\mathrm{c}-\mathrm{Myc}$ through a proteasome and HIF-1 $\beta$-independent mechanism. We previously reported that $\mathrm{HIF}-1 \alpha$ interacts with and increases the transcriptional activity of $\mathrm{C} / \mathrm{EBP} \alpha^{9,17}$ Thus, we assayed the effect of $\mathrm{C} / \mathrm{EBP} \alpha$ on $\mathrm{c}-\mathrm{Myc}$ expression.

In the engineered $\mathrm{U} 937 \mathrm{~T}^{\mathrm{C} / \mathrm{EBP} \alpha}$ cells, $\mathrm{C} / \mathrm{EBP} \alpha$ protein was significantly induced after tetracycline withdrawal (Supplementary Figure S9A), as described previously. ${ }^{9}$ Upon the conditional induction of $\mathrm{C} / \mathrm{EBP} \alpha, \mathrm{c}-\mathrm{Myc}$ was significantly downregulated at both the mRNA and protein levels (Supplementary Figures S9A and B). We stably introduced shRNA against C/EBP $\alpha$ expression (shR-C2) in U937T ${ }^{\mathrm{HIF}-1 \alpha}$ cells. ${ }^{9}$ As depicted in Supplementary Figure S9C, shR-C2 reduced $\mathrm{C} / \mathrm{EBP} \alpha$ protein with no influence on $\mathrm{HIF}-1 \alpha$ protein.

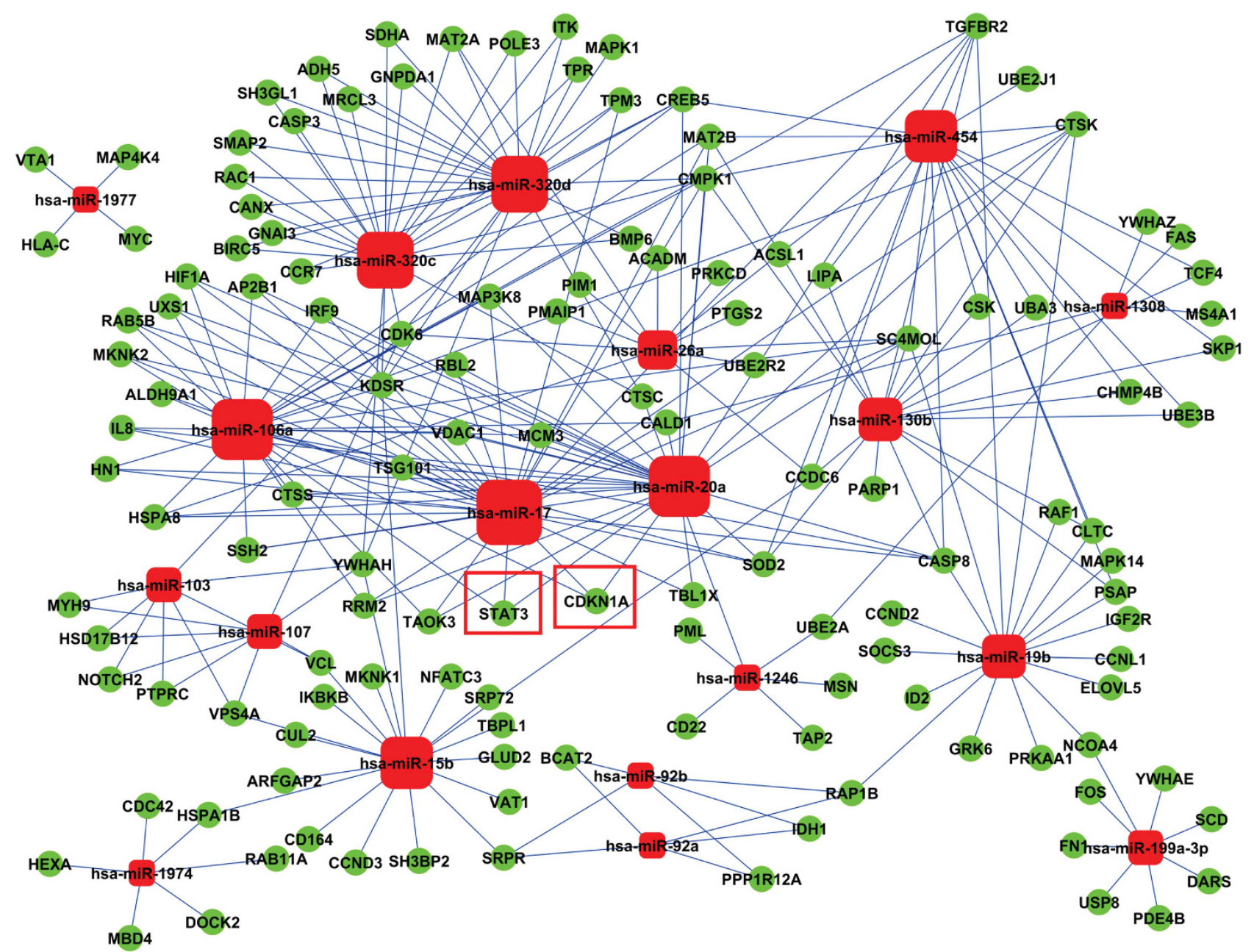

Figure 2 miRNA-target gene network analysis. Red box nodes represented miRNAs and green cycle nodes represented target genes. Edges indicated the inhibitive effect of miRNAs on target genes. The red boundary square showed the two putative target genes of miR-17 and miR-20a, p21 (or CDKN1A), and STAT3 
a

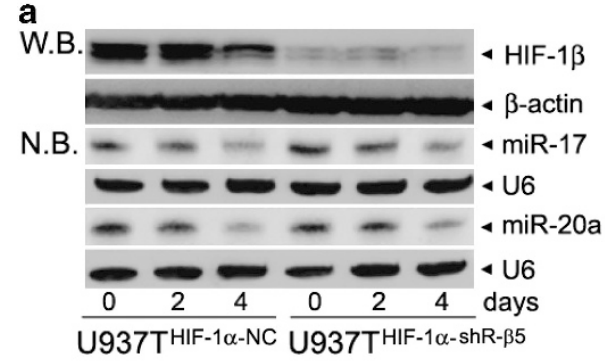

C

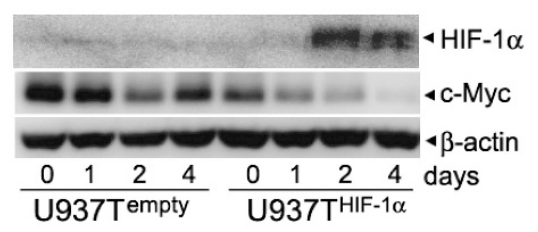

e

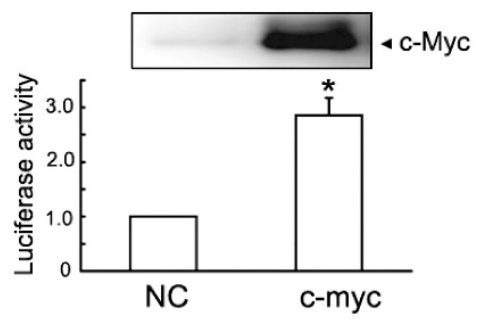

b
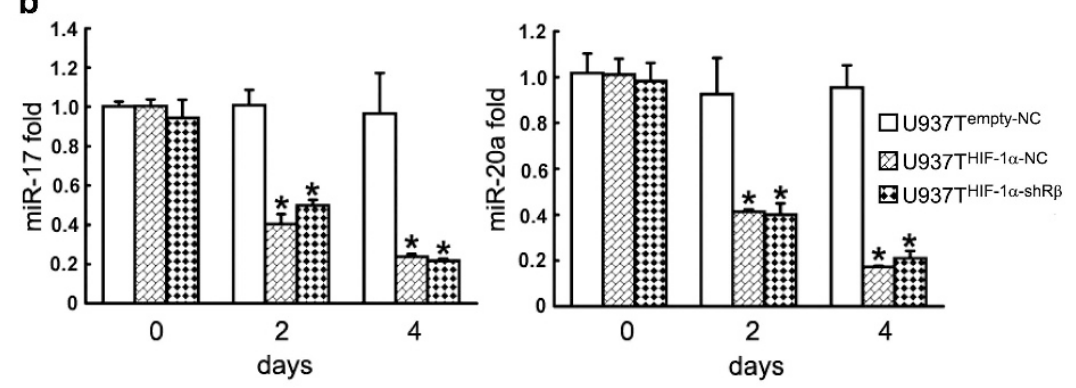

d
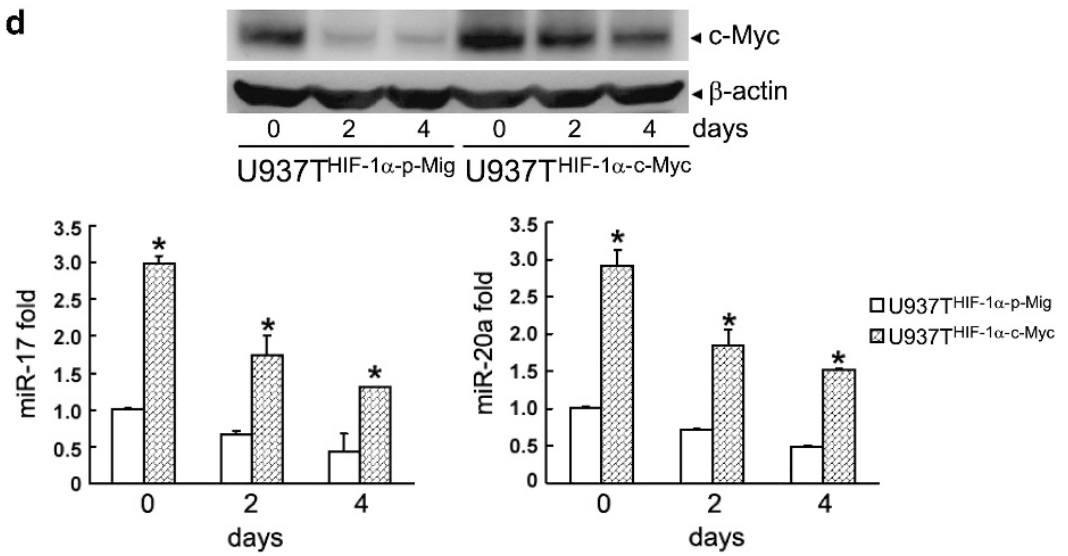

Figure 3 HIF-1 $\alpha$ inhibits miR-17 and miR-20a expression by downregulating c-Myc, but independently of HIF-1 $\beta$. (a and $\mathbf{b}$ ) MiR-17 and miR-20a expressions in U937T ${ }^{\text {HIF-1 } \alpha}$

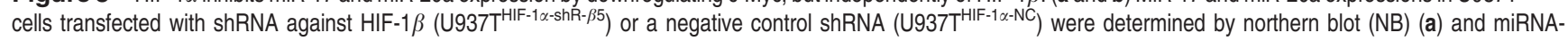
specific qRT-PCR (b). Triplicate assays were done for each RNA sample and the relative amount of each miRNA was normalized to U6 snRNA. The symbol * indicated $P<0.05$. The HIF-1 $\beta$ protein was detected by western blot (WB) which was shown in the upper panel of (a). (c) Decreased c-Myc protein after conditional induction of HIF-1 $\alpha$ in U937 $\mathrm{T}^{\text {empty }}$ and U937 $\mathrm{T}^{\mathrm{HIF-1 \alpha}}$ cells. (d) U937 $\mathrm{T}^{\mathrm{HIF}-1 \alpha}$ cells were stably transfected with c-Myc-expressing retrovirus or control vector (p-Mig) (grouped as U937 $\mathrm{T}^{\mathrm{HIF}-1 \alpha-c-M y c}$ and U937T ${ }^{\text {HIF-1 } \alpha-p-M i g}$ ). MiR-17 (left) or miR-20a (right) expression in above cells was determined by miRNA-specific qRT-PCR. Triplicate assays were done for each RNA sample and the relative amount of each miRNA was normalized to U6 snRNA. The symbol * indicated $P<0.05$. The overexpression of c-Myc protein was shown in the upper panel of (d). (e) The normalized luciferase activity in HEK293T cells transfected with the promoter of miR-17-92 (pGL4 prom17) in combination with pcDNA, pcDNA-c-Myc. The symbol * indicated $P<0.05$ to control groups

More intriguingly, the knockdown of $\mathrm{C} / \mathrm{EBP} \alpha$ suppressed HIF-1 $\alpha$-induced downregulation of c-Myc in U937 ${ }^{\mathrm{HIF}-1 \alpha}$ cells at both the mRNA and protein levels (Supplementary Figures $\mathrm{S} 9 \mathrm{C}$ and $\mathrm{D})$. These results suggest that $\mathrm{C} / \mathrm{EBP} \alpha$ mediates the downregulation of c-Myc by HIF- $1 \alpha$.

Ectopic expression of c-Myc restores miR-17 and miR$20 \mathrm{a}$ expression under HIF-1 $\alpha$ induction. To determine whether decreased c-Myc is responsible for the decreased expression of miR-17 and miR-20 upon HIF-1 $\alpha$ induction, we stably transfected c-Myc into U937 $\mathrm{T}^{\mathrm{HIF}-1 \alpha}$ cells (Figure $3 \mathrm{~d}$ ). Our results showed that the stable ectopic expression of c-Myc significantly upregulated miR-17 and miR-20a expression in U937T $T^{\mathrm{HIF}-1 \alpha}$ cells (Figure $3 \mathrm{~d}$ ), which was also confirmed with a miR-17 or miR-20a promoter-driven luciferase assay (Figure $3 e$ ). These results suggest a role of reduced $\mathrm{c}$-Myc expression in the HIF- $1 \alpha$-mediated downregulation of miR-17 and miR-20a.

MiR-17 and miR-20a inhibit HIF-1 $\alpha$-triggered differentiation of AML cell lines. Previously, we reported that HIF- $1 \alpha-$ induced differentiation of AML cells is independent of its transcriptional activity. ${ }^{9}$ These results parallel HIF- $1 \alpha$ regulation of $\mathrm{miR}-17$ and $\mathrm{miR}-20 \mathrm{a}$ described here. Thus, we considered whether the downregulation of $\mathrm{miR}-17$ and miR-20a is related to hypoxia/HIF- $1 \alpha$-induced differentiation in leukemic cells. For this purpose, we infected U937T ${ }^{\text {empty }}$ and U937T ${ }^{\mathrm{HIF}-1 \alpha}$ cells with empty vector ( $\mathrm{p}-\mathrm{Mig}$ ) or miR-17/ miR-20a-expressing retroviruses carrying GFP. Then, GFP-positive U937T ${ }^{\text {empty }}$ and U937 $T^{\mathrm{HIF}-1 \alpha}$ cells were sorted by flow cytometry and the expression of miR-17 and miR-20a was validated by northern blot (Figure $4 \mathrm{a}$ ). Consistent with the previous study, ${ }^{9}$ HIF- $1 \alpha$ induction significantly inhibited growth and induced differentiation of U937T ${ }^{\mathrm{HIF}-1 \alpha}$ cells (Figures 4b-f). However, ectopic expression of miR-17 or miR-20a partially rescued the growth inhibition and $\mathrm{G}_{1}$ arrest (Figures $4 \mathrm{~b}$ and $\mathrm{c}$ ), and attenuated HIF-1 $\alpha$-triggered differentiation, as determined by decreased percentage of CD11cpositive cells, cell morphology, and decreased nitroblue tetrazolium (NBT) reduction (Figures 4d-f). The same results were obtained with NB4, a different $A M L$ cell line (Supplementary Figures S10C and D). These results suggest that decreased miR-17 and miR-20a contribute to HIF-1 $\alpha$ triggered differentiation of AML cell lines.

MiR-17 and miR-20a directly target p21 and STAT3. Based on the observation that downregulation of miR-17 and miR-20a contributes to HIF- $1 \alpha$-induced AML cell 
a
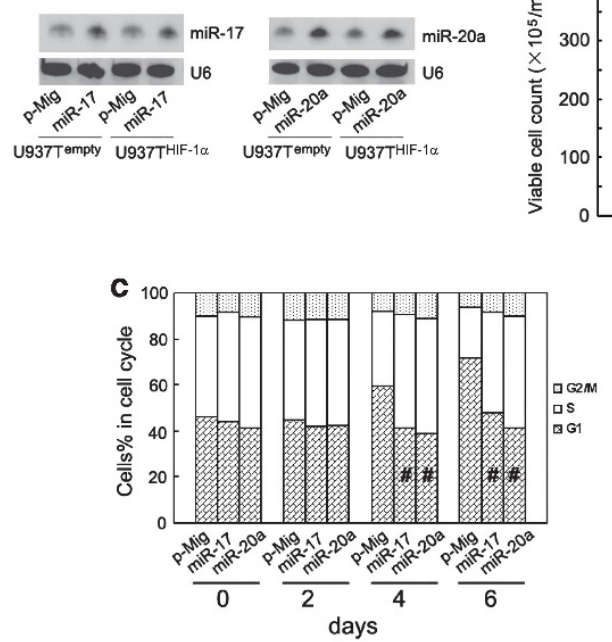

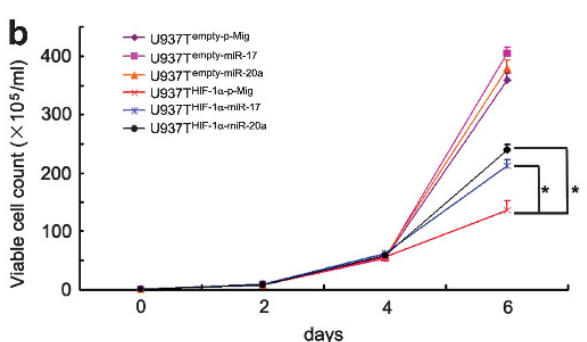

d

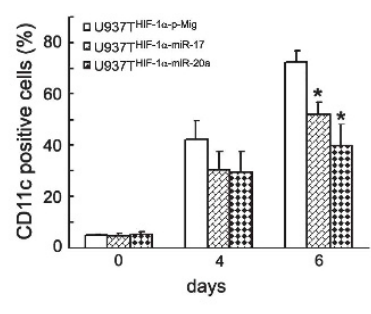

e
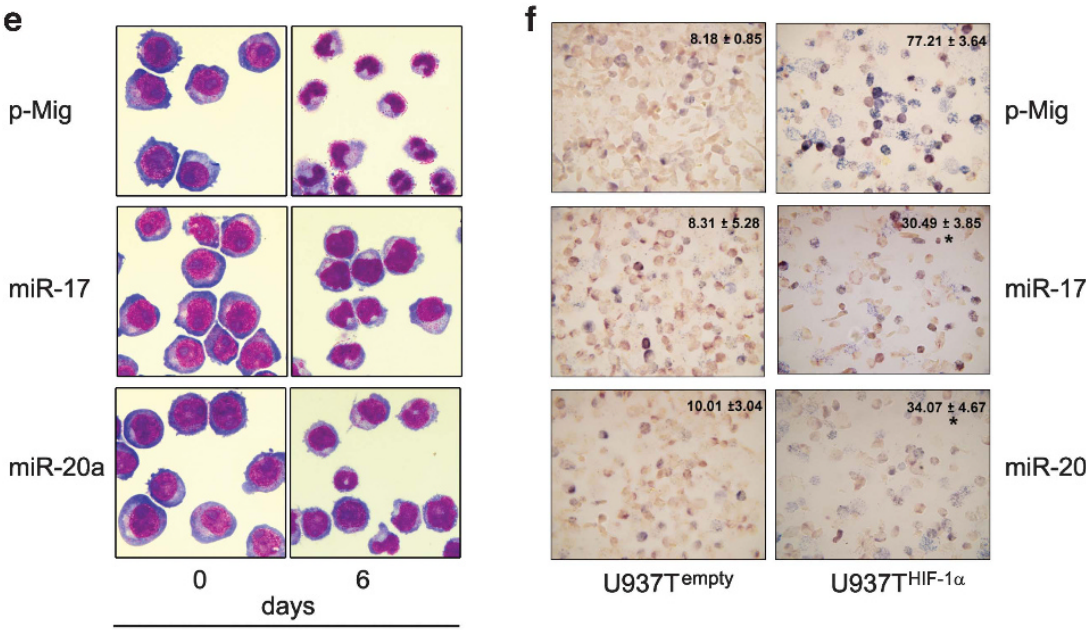

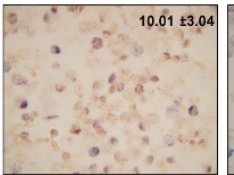

U937Tempty

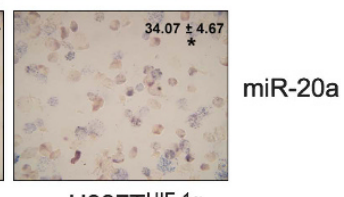

U937THIF-1 $\alpha$

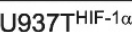

Figure 4 MiR-17 or miR-20a inhibits HIF-1 $\alpha$-triggered growth arrest and granulocytic differentiation of U937 cells. (a) Validation of overexpression of miR-17 and miR-20a

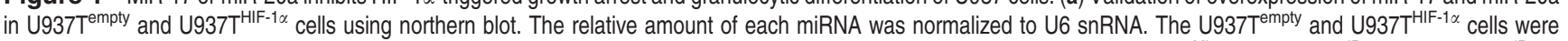

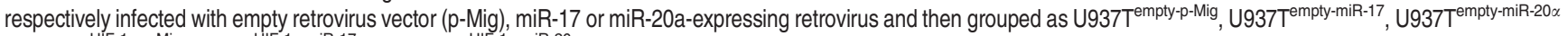

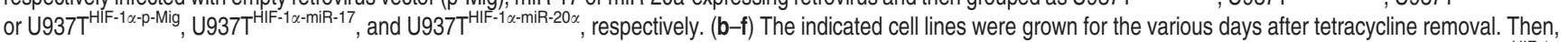
the proliferation and differentiation were measured as below: (b) viable cell numbers of the above six transformants, (c) cell-cycle distribution of the three U937T ${ }^{\text {HIF-1 } \alpha}$ transformants, (d) CD11c-positive cells of the three U937 $T^{\text {HIF-1 } 1 \alpha}$ transformants (\%), (e) cell morphology of the three U937T ${ }^{\text {HIF-1 } \alpha}$ transformants, and (f) NBT reduction of the six transformants ( 6 days after tetracycline removal). The symbols * and \# represented $P<0.05$ compared respectively with U937T ${ }^{\text {HIF-1 } \alpha-p-M i g}$ cells

differentiation, we performed functional analysis of miRNAs using the Kyoto Encyclopedia of Genes and Genomes (KEGG). The results revealed that 48 signal transduction pathways were regulated (Supplementary Excel 3). This includes some pathways that were previously reported as closely related to cell differentiation including the AML activated cell cycle, and the Jak-STAT signaling pathways (Supplementary Figure S11). ${ }^{18-20}$ Meanwhile, among all computationally predicted target genes of miR-17 and miR-20a, p21 and STAT3 stood out as having been reported to be involved in the cell cycle and the Jak-STAT signaling pathways. ${ }^{21,22}$ Moreover, these two target genes were only regulated by miR-17, miR-20a, and miR-106a (Figure 2). Therefore, the relation of miR-17 and miR-20a to p21 and STAT3 might be of great importance to HIF- $1 \alpha$-induced AML cell differentiation. Indeed, p21 and STAT3 proteins were progressively upregulated on days 2 and 4 after tetracycline removal in U937 $T^{\text {HIF-1 } \alpha}$ but not in U937T empty cells (Figure 5a), which paralleled the decreased expression of miR-17 and miR-20a. More intriguingly, ectopic expression of miR-17 and miR-20a reduced the protein levels of p21 and STAT3 on days 2 and 4 after tetracycline removal in U937T HIF-1 $\alpha$ cells (Figure $5 b$ ), suggesting that p21 and STAT3 may be direct targets of miR-17 and miR-20a. To validate this, we performed a $3^{\prime}$ UTR luciferase reporter assay. A miRNA:mRNA alignment analysis clearly showed that the wild-type $3^{\prime}$ UTR of p21 and STAT3 contains two miR-17/ miR-20a binding sites (Figure $5 \mathrm{c}$ ). Thus, they were cloned immediately upstream of the firefly luciferase gene in the pMIR-REPORT vector. The relative luciferase activity of the 
a

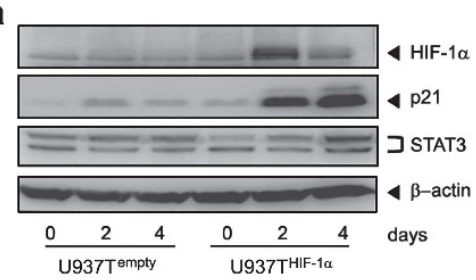

b

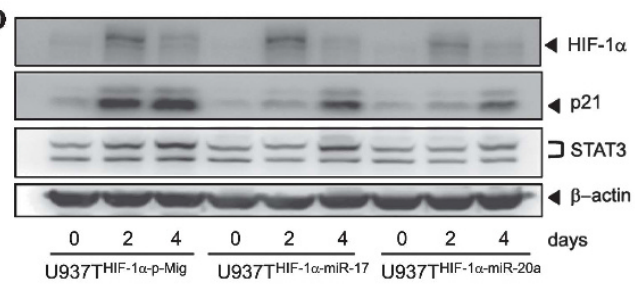

c

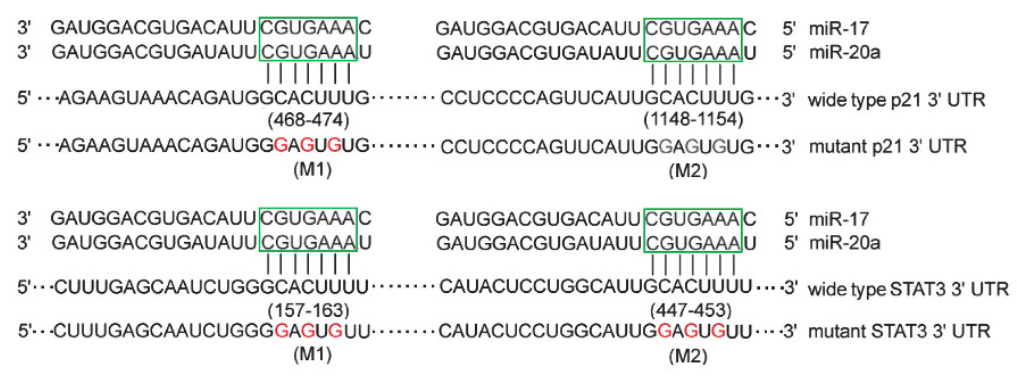
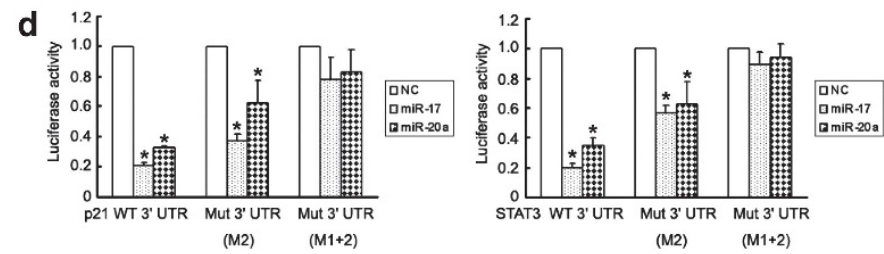

Figure 5 p21 and STAT3 are direct target genes of miR-17/miR-20a. (a) Validation of p21 and STAT3 protein levels after conditional HIF- $1 \alpha$ induction in U937T ${ }^{\text {empty }}$ and U937T ${ }^{\text {HIF-1 } \alpha}$ cells. (b) Ectopic expression of miR-17 or miR-20a downregulated p21 and STAT3 expression in U937T ${ }^{\text {HIF- } 1 \alpha}$ cells. $\beta$-Actin was shown as a loading control. (c) The sequence alignment of the p21 and STAT3 3' UTRs including the predicted miR-17 or miR-20a target site sequence (in 6 boundary square). Mutation of the miR17 or miR-20a target site sequence was shown below (red is the mutants). (d) Luciferase reporter assays to confirm targeting of p21 (left) and STAT3 (right) $3^{\prime}$ UTR by miR-17 or miR-20a. The data were means from three independent experiments. The abbreviations are shown as: the full-length $3^{\prime}$ UTR of p21 or STAT3 ( $3^{\prime}$ UTR WT), only one mutation of the second conserved sites ( $3^{\prime}$ UTR mutant M2) and double mutations of both conserved sites ( $3^{\prime}$ UTR mutant M1 +2$)$. The symbols * indicated $P<0.05$ to control groups

construct with wild-type $3^{\prime}$ UTR of p21 or STAT3 was significantly repressed following the transfection of miR-17 or miR-20a (Figure 5d). Furthermore, the repression of relative luciferase activity was clearly abrogated when single (M2) and especially double (M1 + M2) conserved sites were mutated in the $3^{\prime}$ UTR of p21 or STAT3 (Figure 5d). All these data support the conclusion that miR-17 or miR-20a may suppress both p21 and STAT3 protein expression through directly targeting their $3^{\prime}$ UTR at the post-transcriptional level.

MiR-17 and miR-20a counteract the effects of HIF-1 $\alpha$ by inhibiting p21 and STAT3. To determine whether miR-17/20a acts through p21 and STAT3 to inhibit the effects of HIF- $1 \alpha$ on AML cell lines, we first knocked down the expression of p21 and STAT3. U937T ${ }^{\text {empty }}$ and U937T $T^{\mathrm{HIF}-1 \alpha}$ cells were stably transfected by shRNAs against p21 (shRp21-1, shR-p21-2), STAT3 (shR-ST-1, shR-ST-2) or luciferase as a control (shR-Luc). With the knockdown of p21 or STAT3 (Supplementary Figures S12A and B), the growth arrest induced by HIF- $1 \alpha$ was partially abrogated (Supplementary Figures S12C and D). Meanwhile, the differentiation of these cells induced by HIF- $1 \alpha$ was also suppressed (Supplementary Figures S12E and F). Next, we investigated whether overexpression of p21 or STAT3 $\alpha$ in the miR-17 or miR-20a overexpressed U937 $T^{\mathrm{HIF}-1 \alpha}$ cells could inhibit the effects of the miRNAs. We infected

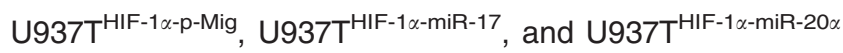
cells with DsRed-tagged p21 or STAT3 $\alpha$-expressing retrovirus with the empty DsRed vector as control. The GFP and DsRed double positive cells were sorted by flow cytometry, and p21 and STAT3 $\alpha$ expression levels were validated by western blot (Supplementary Figure S13). Our results showed that overexpression of p21 in the U937T HIF-1 $\alpha$-miR-17 and U937 $T^{\mathrm{HIF}-1 \alpha-\mathrm{miR}-20 \alpha}$ cells (grouped as miR17-p21 and miR-20a-p21, respectively) abrogated the cell proliferation induced by miR-17 and miR-20a overexpression (grouped as miR17-DsRed and miR-20a-DsRed) (Figure 6a).

Overexpression of $\mathrm{p} 21$ in the U937 $\mathrm{T}^{\mathrm{HIF}-1 \alpha-\mathrm{miR}-17}$ and U937 $\mathrm{T}^{\mathrm{HIF}-1 \alpha-\mathrm{miR}-20 \alpha}$ cells also reversed the effects of miR-17 and miR-20 on cell-cycle arrest (Figure 6b) and differentiation (Figure 6c). Overexpression of STAT3 $\alpha$ led to the same effects as p21 (Figures $6 \mathrm{~d}-\mathrm{g}$ ). Taken together, these results suggest that miR-17 or miR-20a inhibits HIF- $1 \alpha$-induced growth arrest and differentiation by inhibiting p21 and STAT3 expression.

MiR-20a inhibits U937 cell differentiation induced by HIF-1 $\alpha$ and promotes U937 cell proliferation in vivo. To further evaluate the role of miR-20a in vivo, we used a xenograft model of increasing immune deficiency: NOD/ SCID mice treated with anti-CD122 antibody to deplete innate immune cells. The anti-CD122 antibody directs against the IL-2R $\beta$ chain and targets several mature 


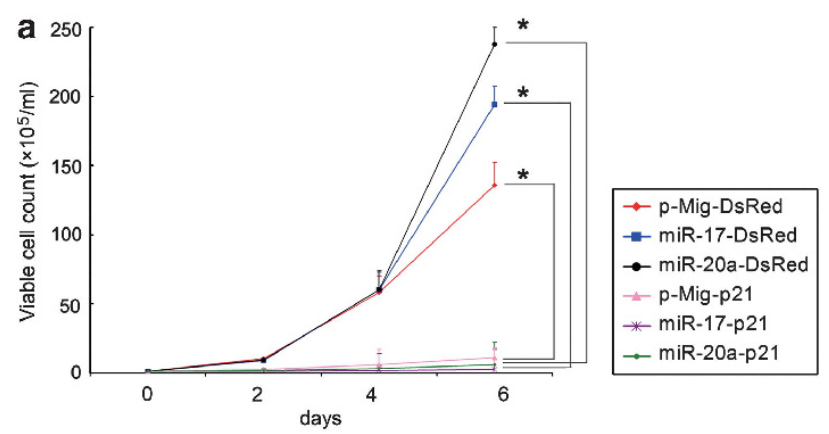

b

c
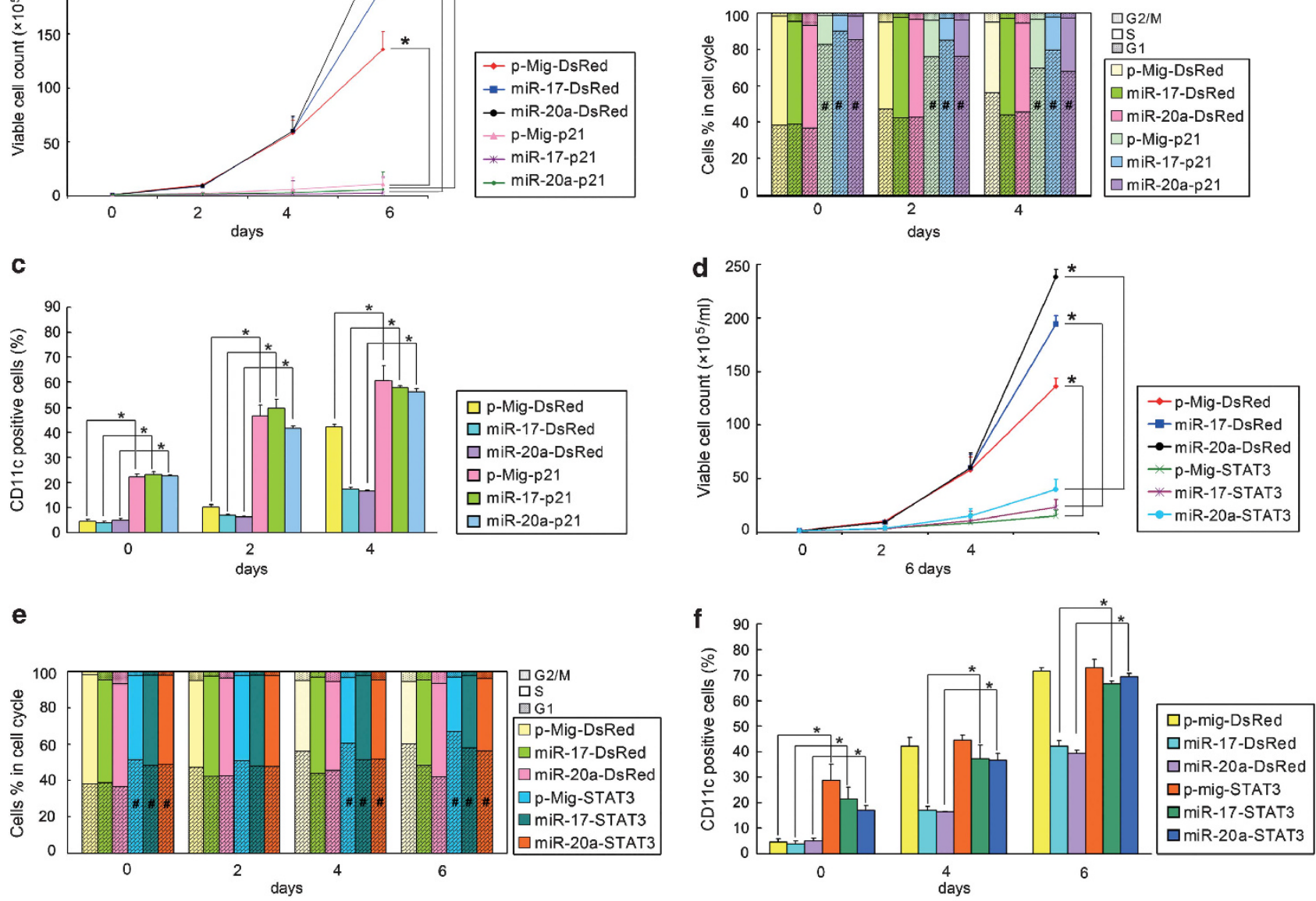

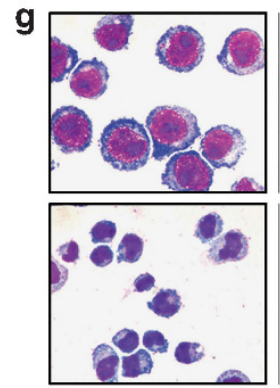

p-Mig-DsRed

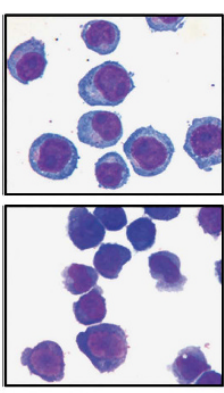

miR-17-DsRed

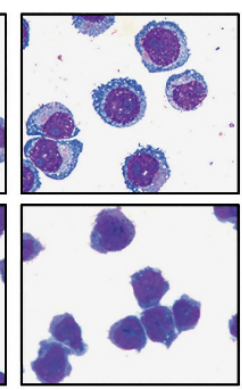

miR-20a-DsRed

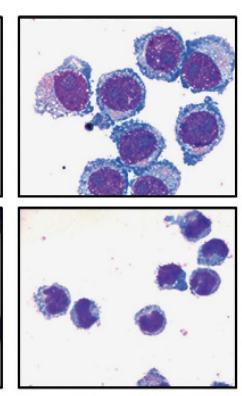

p-Ming-STAT3

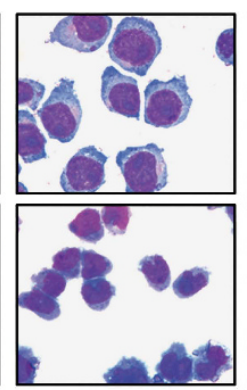

miR-17-STAT3

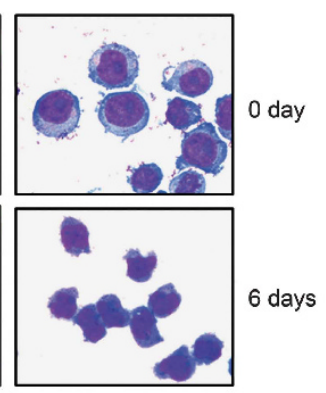

miR-20a-STAT3

Figure 6 MiR-17 and miR-20a counteract the effects of HIF-1 $\alpha$ by inhibiting p21 and STAT3. Growth curve (a), cell-cycle distribution (b), and CD11c-positive cells (\%) (c) of U937 $\mathrm{T}^{\text {HIF-1 } \alpha-p-M i g}$, U937 $T^{\text {HIF-1 } \alpha-m i R-17}$, or U937 $T^{\text {HIF-1 } \alpha-m i R-20 \alpha}$ cells infected with p21-expressing retrovirus (grouped as p-Mig-p21, miR-17-p21, or miR-20a-p21) or control vector (grouped as p-Mig-DsRed, miR-17-DsRed, or miR-20a-DsRed) in different days after tetracycline removal. Growth curve (d), cell-cycle distribution (e), and CD11c-

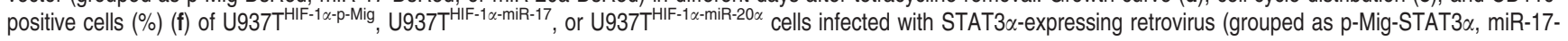
STAT $3 \alpha$, or miR-20a-STAT3 $\alpha$ ) or control vectors (grouped as p-Mig-DsRed, miR-17-DsRed, or miR-20a-DsRed) on indicated days after tetracycline removal. (g) Cell morphology in p-Mig-STAT3 $\alpha$, miR-17-STAT3 $\alpha$, or miR-20a-STAT3 $\alpha$ groups and control vector groups on indicated days after tetracycline removal. The symbols * and \# represented $P<0.05$ compared with respective control vector groups

hematopoietic cell populations including NK cells and macrophages and results in enhanced human engraftment in secondary recipients. ${ }^{23,24}$ The purified human U937T empty-p-Mig, U937T $^{\text {HIF-1 } \alpha-p-M i g}$ and U937T ${ }^{\text {HIF- } 1 \alpha-m i R-20} \alpha$ cells were transplanted into the anti-CD122-treated NOD/SCID mice. Then, we isolated the GFP-positive U937T cells from the bone marrow of the mice and conducted differentiation and morphology assays. Immunocytochemistry staining showed that all these cells stained positive for HIF-1 $\alpha$, but to different degrees. Staining in the U937T ${ }^{\mathrm{HIF}-1 \alpha-p-M i g}$ and U937T $\mathrm{T}^{\mathrm{HIF}-1 \alpha-\mathrm{miR}-20 \alpha}$ cells was significantly stronger than that of U937 $\mathrm{T}^{\mathrm{empty}-\mathrm{p}-\mathrm{Mig}}$ cells, suggesting that the tet-off inducible system was effective in vivo (Figure 7a). Flow cytometry analysis of isolated cells from 
bone marrow revealed that transplantation with $\mathrm{HIF}-1 \alpha$ overexpression cells (U937 $\mathrm{T}^{\mathrm{HIF}-1 \alpha-\mathrm{p}-\mathrm{Mig}}$ group) resulted in a significantly lower percentage of human cells when compared with control $(0.9$ versus $23.0 \%$ in 21 days after the transplantation). On the other hand, miR-20a overexpression increased the percentage of U937 $\mathrm{T}^{\mathrm{HIF}-1 \alpha}$ cells from 0.9 to $3.5 \%$, when equal numbers of cells were transplanted (Figure 7b). Most importantly, consistent with our in vitro results, we found that HIF-1 $\alpha$ increased the expression of CD11c in isolated human U937 cells 10 days after transplantation, while miR-20a attenuated this increase $(68.52 \pm 1.46$ versus $47.84 \pm 2.15 \%)$ (Figure $7 \mathrm{c})$. Furthermore, the morphology of $U 937$ cells isolated from bone marrow validated the observation that U937 cell differentiation induced by HIF- $1 \alpha$ was partially inhibited by miR-20a (Figure 7d). It is worthwhile to mention that the rescue by miR-20a expression is modest compared with what was observed in vitro. This is possibly due to the longer time course compared with the in vitro experiments (the in vivo experiments were conducted 21 days (for proliferation) and 10 days (for differentiation) after transplantation, respectively, while the in vitro experiments were conducted 6 days after tetracycline withdrawal). Moreover, other HIF- $1 \alpha$-regulated factors such as gelactin- $1^{15}$ and the bone marrow environment could also have some influence on the transplanted human cells. Collectively, our data indicate that miR-20a inhibits the cellular differentiation and reduced proliferation induced by $\mathrm{HIF}-1 \alpha$ in leukemic cells in vivo.

\section{Discussion}

In this study, we comprehensively analyzed how HIF- $1 \alpha$ affected miRNA expression by generating HIF-1 $\alpha$ inducible AML cells. Through this, we provided the first demonstration that HIF-1 $\alpha$ downregulates the expression of miR-17 and miR20a. Recently, a series of studies reported that the expression of the miR-17-92 cluster can be regulated by various transcription factors, including c-Myc, E2F, AML1, cyclin D1, and $p 53$ in diverse cell types. ${ }^{16,25-28}$ As a transcription factor, the transcriptional activity of $\mathrm{HIF}-1 \alpha$ requires its heterodimerization with HIF-1 $\beta$. However, when HIF-1 $\beta$ expression was silenced by its specific shRNA, inducible expression of $\mathrm{HIF}-1 \alpha$ still repressed miR-17 and miR-20a. Hence, we extrapolated that $\mathrm{HIF}-1 \alpha$ protein regulates $\mathrm{miR}-17$ and miR-20a expression through a transcription-independent manner. Of great interest, HIF-1 $\alpha$ induction also inhibited the expression of c-Myc, and we showed that this was due to $\mathrm{C} / \mathrm{EBP} \alpha$. Furthermore, we proved that reduced c-Myc expression contributes to HIF-1 $\alpha$ induced repression of $\mathrm{miR}-17$ and miR-20a expression. It is noteworthy that a previous study reported that the expression levels of the miR-17-92 cluster were reduced in hypoxic cells containing wild-type p53 but not p53-deficient cells, and the repression of the miR-17-92 cluster under hypoxia was independent of c-Myc in colon cancer cell lines. ${ }^{27}$ However, U937T cells do not express p53 (Supplementary Figure S14) and $\mathrm{HIF}-1 \alpha$ still represses miR-17 and miR-20a expression. The contradiction with the previous report may be due to the different cellular contexts of leukemia and solid tumors. a

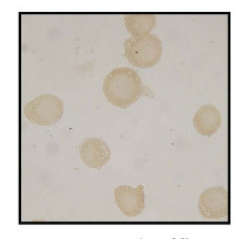

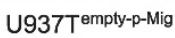

U937T

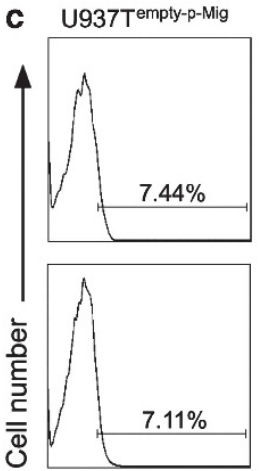

CD11c

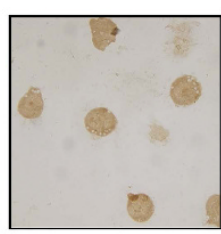

U937T ${ }^{\text {HIF-1 } \alpha-p-M i g}$
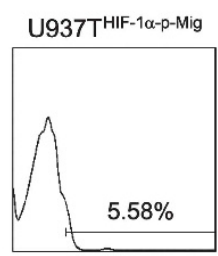

U937T ${ }^{\text {HIF-1 } \alpha-m i R-20 a}$

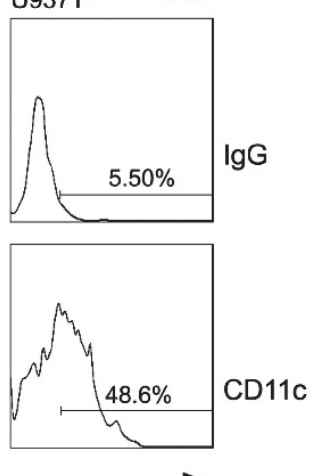

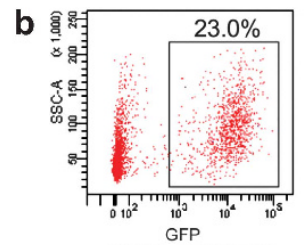

UFP
U93
empty-p-Mig

d

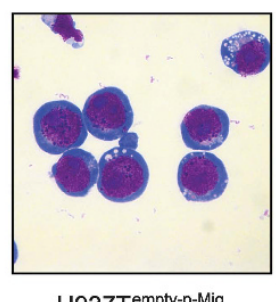

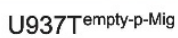

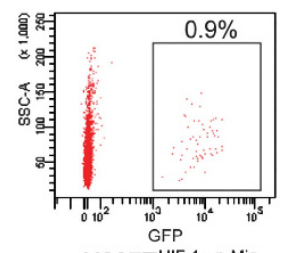

U937T HIF-1 $\alpha-p-M i g$

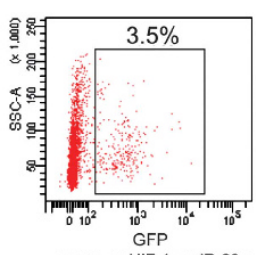

U937T HIF-1 $\alpha-$ miR-20a
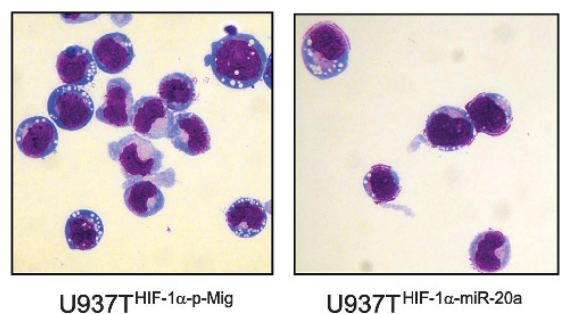

Figure 7 Ectopic expression of miR-20a in U937T $\mathrm{T}^{\mathrm{HIF}-1 \alpha}$ cells impairs the granulocytic differentiation induced by HIF-1 $\alpha$ and promotes proliferation in vivo. (a) Immunocytochemical staining of HIF-1 $\alpha$ in the U937 cells isolated from the bone marrow of the engrafted mice on day 10 after the transplantation. Mice were injected with U937T ${ }^{\text {empty-p-Mig }}$ cells (control, left), U937T cells with inducible HIF-1 $\alpha$ (U937T $T^{\text {HIF-1 } \alpha-p-M i g}$, middle), or U937T ${ }^{\text {HIF-1 } \alpha}$ cells infected with miR-20a-expressing retrovirus (U937T $^{\text {HIF-1 } \alpha-m i R-20 \alpha}$, right), respectively. (b) miR-20a affected the U937 cell proliferation in the bone marrow of the engrafted mice. A representative dot plot analysis from one of three independent experiments. Numbers were shown as the percentage of GFP-positive cells from $1 \times 10^{5}$ acquired bone marrow cells on day 21 after the transplantation. (c) CD11c-positive cells (\%) in GFP-positive cells isolated from the bone marrow of the engrafted mice on day 10 after the transplantation ( $n=5$ ). (d) Cell morphology of GFP-positive cells isolated from the bone marrow of the engrafted mice on day 10 after the transplantation $(n=5)$ 
MiR-17 and miR-20a belong to a highly conserved gene cluster-miR-17-92, a miRNA polycistron also known as oncomir-1, and may have parallel roles through regulating the same target genes because they contain the same seed sequence. The expression levels of miR-17 and miR-20a have great importance since miR-17 inhibition affects cancer cell growth only in cells that have high expression of the miR17-92 cluster, whereas other cell types with lower expression of miR-17-92 remain unaffected. ${ }^{29}$ Previous expression profiling studies have shown that miR-17 and miR-20a are overexpressed in a wide variety of solid tumors and hematopoietic malignancies, such as diffuse large B-cell lymphomas (DLBCLs), mantle cell lymphomas, and Burkitt's lymphomas. ${ }^{30-32}$ Our current study also shows that the expression of miR-17 or miR-20a is significantly higher in U937 cells compared with cord blood mononuclear cells (CBMC) (Supplementary Figure S15).

In addition, the precise roles of the miR-17-92 cluster in hematopoietic development and hematopoietic malignancies remain controversial according to different reports. In the absence of miR-17-92, hematopoietic development proceeds normally, except for an isolated defect in B-cell development. ${ }^{33}$ However, in the in vitro differentiation system of human $\mathrm{CD}_{34}{ }^{+}$hematopoietic progenitor cells, miR-17, miR-20a, and miR-106a control monocytopoiesis. ${ }^{25}$ Because previous investigations proposed that HIF- $1 \alpha$ can trigger AML cells to undergo differentiation through a transcriptionindependent mechanism, we tried to explore the potential role of the reduced $\mathrm{miR}-17$ and miR-20a expression in $\mathrm{HIF}-1 \alpha$-induced AML cell differentiation. Our study strongly suggests that the downregulation of $\mathrm{miR}-17$ and miR-20a plays a role in AML cell differentiation induced by HIF-1 $\alpha$ or hypoxia in vitro and in vivo, because their ectopic expression effectively antagonized hypoxia or HIF-1 $\alpha$ induction-triggered NB4 or U937 cell differentiation. Consistent with the effects of overexpressing miR-17 and miR-20a, c-Myc overexpression also partly attenuated HIF- $1 \alpha$-induced cell-cycle arrest and differentiation (Supplementary Figure S16).

KEGG and miRNA-target gene network analysis suggests that p21 and STAT3 are among the strongest computationally predicted targets of $\mathrm{miR}-17$ and $\mathrm{miR}-20 \mathrm{a}$, and both genes are likely to participate in the cell cycle and the Jak-STAT signaling pathways. p21 is an inhibitor of cell-cycle progression, exerting its effect through interaction with cyclindependent kinase (CDK) complexes and arresting cells in G0/1 phase. ${ }^{21}$ Moreover, p21 is closely correlated with the induction of differentiation in U937 cells, which can occur independently of p53. ${ }^{18}$ STAT3 activation in myeloid cell lines promotes differentiation of neutrophils and macrophages, although overexpression of STAT3 partially impairs macrophage differentiation of M1 cells. ${ }^{34}$ p21 has previously been reported to be a target of $\mathrm{miR}-17$ and miR-20a in MLL leukemia stem cells and gastric epithelial cells, and more recently in iPS cells. ${ }^{35-37}$ STAT3 has also been found to be a target of miR-17 and miR-20a in mouse ES cells and mouse myeloid-derived suppressor cells. ${ }^{38,39}$ Here, we show that miR-17 and miR-20a can target the p21 and STAT3 3 ' UTR to inhibit the expression of p21 and STAT3 in human cells. STAT3 exists in two isoforms, STAT3 $\alpha$ and STAT3 $\beta$, and they share a similar $3^{\prime}$ UTR sequences. Consequently, miR-17 and
miR-20a can directly repress both isoforms, which are consistent with our data. The ratio of STAT3 $\alpha /$ STAT3 $\beta$ protein is reported to decrease with myeloid cell maturation and activation. ${ }^{40}$ However, the difference of the ratio of STAT3 $\alpha$ l STAT3 $\beta$ is not statistically significant in our report, which suggests that miR-17 and miR-20a repress both isoforms equally. Furthermore, STAT3 $\alpha$ itself may promote myeloid cell differentiation and this was the reason why we only overexpress STAT3 $\alpha$ in the knockdown and rescue experiments.

In summary, we demonstrated that HIF- $1 \alpha$ downregulates the expressions of miR-17 and miR-20a through a mechanism that is dependent of $\mathrm{c}-\mathrm{Myc}$ but independent of its transcription partner $\mathrm{HIF}-1 \beta$. Furthermore, we uncovered the important role of miR-17 and miR-20a in HIF- $1 \alpha$-induced myeloid differentiation and growth arrest in $\mathrm{AML}$ cells in vitro and in vivo and verified that $\mathrm{p} 21$ and STAT3 are their functional target genes. These discoveries should shed new insights for using miRNAs as the novel therapeutics for the treatment of AML.

\section{Materials and Methods}

Cell lines, cell cycle, and differentiation assay. To provide direct evidence for the role of HIF- $1 \alpha$ in AML cell differentiation and its mechanisms, we generated myeloid leukemic U937T transformants (U937T ${ }^{\text {HIF-1 } \alpha}$ cells), in which HIF-1 $\alpha$ was tightly induced by tetracycline withdrawal. U937T ${ }^{\text {empty }}$ and U937 $\mathrm{T}^{\mathrm{HIF}-1 \alpha}$ cells were cultured in RPMI-1640 medium (Sigma-Aldrich, St. Louis, MO, USA) supplemented with $10 \%$ fetal bovine serum (FBS; HyClone, Logan, UT, USA), $1 \mu \mathrm{g} / \mathrm{ml}$ of tetracycline and $0.5 \mu \mathrm{g} / \mathrm{ml}$ of puromycin (Sigma-Aldrich). ${ }^{9}$ U937T stable transformants with inducible C/EBP $\alpha$ and empty vector (U937 ${ }^{\mathrm{C} / \mathrm{EBP} \alpha}$ and U937T ${ }^{\text {PTRE}}$ ) were established as described previously. ${ }^{15}$ All cell lines were cultured in $5 \% \mathrm{CO}_{2} / 95 \%$ air in a humidified atmosphere at $37^{\circ} \mathrm{C}$. For hypoxic treatment, the NB4 and U937 transformants were cultured in a specially designed hypoxia incubator (Thermo Electron, Forma, MA, USA) in an atmosphere that consists of $94 \% \mathrm{~N}_{2}, 5 \% \mathrm{CO}_{2}$, and $1 \% \mathrm{O}_{2}$. In all experiments, cell viability exceeded $95 \%$, as determined by a trypan-blue exclusion assay. For morphological characterization, cells were collected onto slides by cytospinning (Shandon, Runcorn, UK), stained with Wright's stain and examined by light microscopy (Olympus, BX-51, Tokyo, Japan). The differentiation antigens were measured using phycoerythrin (PE)- or allophycocyanin (APC)-labeled anti-CD11c, CD11b, or CD14, with isotype controls (BD Biosciences, San Jose, CA, USA), via flow cytometry (Beckman-Coulter, Miami, FL, USA). The NBT reduction test was performed as previously described. ${ }^{15}$ The distribution of nuclear DNA contents was analyzed by flow cytometry (Beckman-Coulter).

MiRNA microarray analysis. Microarray analysis was performed on $5 \mu \mathrm{g}$ of total RNA from 18 samples including 3 separate samples of U937 $\mathrm{T}^{\text {empty }}$ or U937 $\mathrm{T}^{\mathrm{HIF}-1 \alpha}$ cells at 0,2 , and 4 days after tetracycline removal, which were size fractionated using a YM-100 Microcon centrifugal filter (Millipore, Billerica, MA, USA) and the small RNAs ( $<300 \mathrm{nt}$ ) isolated were $3^{\prime}$-extended with a poly(A) tail using poly $(A)$ polymerase. An oligo nucleotide tag was then ligated to the poly $(A)$ tail for later fluorescent dye staining. Hybridization was performed overnight on a $\mu$ Paraflo microfluidic chip using a micro-circulation pump (Atactic Technologies, Houston, TX, USA). On the microfluidic chip, each detection probe consisted of a chemically modified nucleotide coding segment complementary to target miRNAs (from miRBase; http://microrna.sanger.ac.uk/sequences/) and a spacer segment of polyethylene glycol to extend the coding segment away from the substrate. The detection probes were made by in situ synthesis using PGR (photogenerated reagent) chemistry. The hybridization melting temperatures were balanced by chemical modifications of the detection probes. Hybridization was done using $100 \mu \mathrm{l} 6 \times$ SSPE buffer $\left(0.90 \mathrm{M} \mathrm{NaCl}, 60 \mathrm{mM} \mathrm{Na} 2 \mathrm{HPO}_{4}, 6 \mathrm{mM}\right.$ EDTA, pH 6.8) containing $25 \%$ formamide at $34^{\circ} \mathrm{C}$. After hybridization, detection was performed using fluorescence labeling with tag-specific Cy5 dyes. Hybridization images were collected using a laser scanner (GenePix 4000B, Molecular Device, Sunnyvale, CA, USA) and digitized using Array-Pro image analysis software (Media Cybernetics, Silver Spring, MD, USA). Data were analyzed by first subtracting the background and then normalizing the signals using a LOWESS filter (Locally weighted Regression). 
The ratio of the three or six sets of detected signals $\left(\log _{2}(2 \mathrm{~d}\right.$ or $\left.4 \mathrm{~d} / 0 \mathrm{~d})\right)$ and $P$-values of the one-way ANOVA test were calculated; differentially detected signals were those with a $P$-value of $<0.05$. Regulated miRNAs were divided into high or low signal using a signal intensity value of 500 normalized signal units.

GO terms and KEGG pathway annotation based on miRNA expression profile. We pooled the reported and predicted targets of filtered miRNAs from the TargetScanHuman database (http://www.targetscan.org/). Bioinformatics analyses were performed using Matlab to identify the significant functions and significant pathways of the miRNA target genes. The top $25 \%$ miRNA targets that had been assigned the highest numbers of miRNA interaction sites were collected, and subjected to GO term analysis. GO analysis was applied in order to organize genes into hierarchical categories and uncover the miRNAgene regulatory network on the basis of biological process and molecular function. To identify significant functions, GO enrichment analysis was performed according to the GO database with a $P$-value of $<0.01$ as calculated by Fisher's exact test and the $\chi^{2}$ test and corrected by a false discovery rate (FDR and an FDR of $<0.01$ ). In addition, enrichment was regarded as a measure of the significance in gene function to find those GOs with a more concrete function description in the differential miRNA. Similarly, significant pathways were identified based on the KEGG (http://www.genome.jp/kegg/)

MiRNA-GO network. MiRNA-GO network is built according to the relationship of miRNAs and significant GOs. In the miRNA-GO network, the circle represents $G O$ and the shape of red square represents miRNAs, and their relationship was represented by one edge. The center of the network was represented by degree. Degree of miRNA means how many links one miRNA regulates GOs. The core miRNAs in the network always have the highest degrees.

MiRNA-target gene network. Differentially miRNA target genes in significant GO and pathway categories, obtained from GO and pathway analyses, were analyzed by miRNA-target gene network. The relationship of the miRNAs and target genes was counted by their differential expression values, and according to the interactions of miRNA and target genes in Sanger miRNA database to build the miRNA-target gene network. In the miRNA-target gene network, the circle represents target gene and the shape of square represents miRNA, and their relationship is represented by one edge. The center of the network was represents by degree. Degree of miRNA means how many links one miRNA regulates target genes. The core miRNAs in the network always have the highest degrees.

Real-time RT-PCR. Total RNA extracted from cells was used to generate cDNA using ImProm-II TM Reverse Transcription System (Promega, Madison, WI, USA) with specific stem-loop primers for miRNA and random primer for mRNA Real-time quantitative PCR was performed using SYBR Green PCR Master Mix (Applied Biosystems, Warrington, UK) in an Applied Biosystems 7300 instrument. The relative RNA amount was calculated with the $\Delta \Delta \mathrm{Ct}$ method and normalized with internal control U6 snRNA (for mature miRNAs) and $\beta$-actin mRNA (for mRNAs). All reactions were run in triplicate. Primer sequences are detailed in Supplementary Table S1.

Western blot. Cell lysates were fractionated by sodium dodecyl sulfate (SDS)polyacrylamide gel electrophoresis and then transferred onto nitrocellulose membrane (Axygen, Union City, CA, USA). After blocking with 5\% non-fat milk in Tris-buffered saline, the membranes were incubated with the antibodies against HIF-1 $\alpha$, HIF-1 $\beta$ (BD Transduction, San Jose, CA, USA), c-Myc, p53 (Santa Cruz, CA, USA), STAT3, p21, and C/EBP $\alpha$ (Cell Signaling, Beverly, MA, USA) followed by horseradish peroxidase (HRP)-linked secondary antibodies (Cell Signaling) for $1 \mathrm{~h}$ at room temperature. Detection was performed by chemiluminescence phototope-HRP kit according to manufacturer's instruction (Cell Signaling). As necessary, blots were stripped and reprobed with anti- $\beta$-actin (Merck, Darmstadt, Germany) antibody as internal controls. All experiments were repeated three times.

DNA constructs. To stably express miR-17 or miR-20a or c-Myc in U937T ${ }^{\text {empty }}$ or U937T ${ }^{H I F-1 \alpha}$ cells and NB4 cells, miR-17 and miR-20a expression cassette containing the human miR-17 and miR-20a hairpin sequence and flanking regions were cloned from human genomic DNA isolated from U937 cells using the primer set in Supplementary Table S1 and inserted into a retrovirus vector containing an IRES-GFP downstream of cloning site with MSCV promoter
(p-Mig). p21 or STAT3 $\alpha$ was stably expressed in relative U937T $T^{\mathrm{HIF}-1 \alpha}$ transformants by inserting their expression cassette into DsRed retrovirus vector, which contains an IRES-DsRed. The GFP or/and DsRed-positive U937T ${ }^{\text {empty }}$ or U937 $T^{\mathrm{HIF}-1 \alpha}$ cells were purified by flow cytometry and then carried out cell cycle and differentiation assay. For construction of luciferase reporter plasmids, p21 and STAT3 $3^{\prime}$ UTR respectively contains two miR-17 and miR-20a matching sites. In all, 468-474 nt and 1148-1154 nt, oriented from the $5^{\prime}$ end of $3^{\prime}$ UTR, were putative binding sites for miR-17 and miR-20a in $3^{\prime}$ UTR of p21 gene. And for STAT3, 157-163 nt and 447-453 nt were putative binding sites. The full-length $3^{\prime}$ UTR of p21 or STAT3, which contains miR-17 and miR-20a-binding sites, was cloned immediately downstream of the firefly luciferase gene in the pMIRREPORT vector after amplification of genomic DNA from human U937 cells using the primer sets in Supplementary Table S1 ( $3^{\prime}$ UTR WT). The mutated $3^{\prime}$ UTRs of respective mRNAs were amplified with the specific primers in which $3 \mathrm{bp}$ in the $3^{\prime}$ UTR of p21 or STAT3 genes corresponding to the position of 2,4 , and 6 oriented from the $5^{\prime}$ terminus of mature miR-17 or miR-20a was mutated ( $3^{\prime}$ UTR mutant M2 or $\mathrm{M} 1+2)$. The mutation included only mutation of second conserved sites ( $3^{\prime}$ UTR mutant M2) and jointly ( $3^{\prime}$ UTR mutant M1+M2). For shRNA experiments, pairs of complementary oligonucleotides against HIF- $1 \alpha$ (shR- $\alpha 14$ and shR- $\alpha 16$ ), HIF-1 $\beta$ (shR- $\beta 2$ and shR- $\beta 5$ ), p21 (shR-p21-1 and shR-p21-2), STAT3 $\alpha$ (shR-ST-1 and shR-ST-2) and C/EBP $\alpha$ (shR-C2) were synthesized by Invitrogen (Shanghai, China), annealed and ligated into pSilencer 3.1-H1-neo vector (Ambion, Austin, TX, USA). Target sequences are provided in Supplementary Table S1.

Luciferase assays. HEK293T cells were seeded in 24-well plates at a density of $2.0 \times 10^{5}$ cells per well and allowed to grow for $24 \mathrm{~h}$ before transfection. Then, each well was transiently co-transfected with $100 \mathrm{ng}$ reporter plasmids of either wild-type or mutant $3^{\prime}$ UTR of STAT3 or p21 construct pMIR-REPORT (Ambion), $60 \mathrm{pmol} \mathrm{NC}$ or miR-17, miR-20a mimics and $10 \mathrm{ng}$ internal control vectorpRL-SV40 (Promega) using lipofectamine 2000. Cell lysates were harvested $36 \mathrm{~h}$ post transfection and then firefly and renilla luciferase activities were measured by the Dual-Luciferase Reporter Assay System (Promega) on a Berthold AutoLumat LB9507 rack luminometer (Rockford, IL, USA). The value of relative luciferase activity denotes the firefly luciferase activity normalized to that of renilla for each assay. To test if c-Myc can regulate miR-17-92 expression, we constructed the promoter of miR-17-92 using pGL4.10 vector (pGL4 prom17) that carried the promoter luciferase assay as previously reported. ${ }^{25}$

Northern blot. Total RNA isolation was performed using the acid phenolguanidinium thiocyanate-chloroform protocol. RNA samples ( $20 \mu \mathrm{g}$ each) were run on $15 \%$ acrylamide urea-denaturing precast gel (Invitrogen, Carlsbad, CA, USA), and transferred onto Hybond- $\mathrm{N}^{+}$membrane (Amersham Biosciences, Little Chalfont, UK). The hybridization was performed overnight with miRCURY LNA miRNA Detection Probes labeled with Digoxin (Exiqon, Vedbaek, Denmark), at $42^{\circ} \mathrm{C}$ in hybridization buffer $\left(7 \% \mathrm{SDS}, 0.2 \mathrm{M} \mathrm{Na}_{2} \mathrm{HPO}_{4}\right)$. Human U6 snRNA was used as a loading control. Probe detection was performed using the DIG Luminescent Detection Kit (Roche, Penzberg, Germany) according to manufacturer's protocol. The optical densities of RNA bands were quantified using Quantity One Software (Bio-Rad, Hercules, CA, USA). The ratio of the densities of miR-17 or miR-20a to that of U6 snRNA represents the relative expression level of each miRNA.

Transplantation of U937T cells in mice. All animal experiments were performed with the approval of the committee for humane treatment of animals at Shanghai Jiao Tong University School of Medicine. The animals were handled under sterile conditions. NOD/SCID repopulation assay by intravenous injection was performed as previously described. ${ }^{24}$ Six- to eight-week-old female NOD/ SCID mice received $350 \mathrm{cGy}$ of total body irradiation, $24 \mathrm{~h}$ before transplantation. Mice were given injections of $200 \mu \mathrm{g}$ purified anti-CD122 antibody into the intraperitoneal cavity immediately following irradiation. The anti-CD122 monoclonal antibody was generated from the hybridoma cell line, TM- $\beta 1$ (from Dr. T Tanaka of Hyogo University of Health Sciences, Kobe, Japan). The purified U937 $T^{\text {empty-p-Mig, }}$ U937T $T^{\text {HIF-1 } \alpha-p-M i g}$, and U937T $T^{\text {HIF-1 } \alpha-m i R-20 \alpha}$ cells (GFP positive) were washed twice' and then intravenously injected $\left(1 \times 10^{7}\right.$ cells suspended in $200 \mu$ l phosphatebuffered saline (PBS) without tetracycline per mouse, $n=10$ for each group), PBS as control group. One week before irradiation, the recipient mice were given acidified, antibiotic water. Neither water nor food contained tetracycline. Mice were monitored and killed at 10 days $(n=5)$ and 21 days $(n=3)$ after the injection for bone-marrow cells harvest. 
Mouse bone-marrow cell isolation and analysis. Samples of bonemarrow cells flushed from both femur and tibia bones were prepared, and the percentage of human U937T cells was determined by GFP and the GFP-positive human U937T cells were isolated by flow cytometry. And, then HIF-1 $\alpha$ expression in human U937T cells was tested by immunocytochemical staining. The differentiation antigen CD11c in GFP-positive U937T cell was measured using PE-labeled anti-CD11c antibody with isotype controls, via flow cytometry. For morphology assay, the purified U937T cells from the bone marrow of three groups were stained with Wright's stain.

Statistical analysis. All experiments were repeated at least three times, and the same results were obtained. All values represent the means with bar as standard deviation of triplicates in an independent experiment. The $t$-test was used to compare the difference between two groups. A value of $P<0.05$ was considered to be statistically significant.

\section{Conflict of Interest}

The authors declare no conflict of interest.

Acknowledgements. This study was supported by National Key Program (973) for Basic Research of China (2009CB918404) and National Science Foundation of China (81170505, 81172521, and 30971107). Additionally, we also gain support from 'Shu Guang' project by Shanghai Municipal Education Commission and Shanghai Education Development Foundation (09SG18), Foundation for the author of National Excellent Doctoral Dissertation of China and a grant from Science and Technology Committee of Shanghai (10QA1404000). We would like to thank Dr. Danica Chen, Yufei Liu, Mary Mohrin, and Livia Wilz of the University of California, Berkeley for the grammar revision of this manuscript. We also thank the LC SCIENCES and Genminix Company for the technical assistances.

\section{Author Contributions}

$\mathrm{MH}$ designed the research, performed most experiments, analyzed the data and drafted the article. QW, QY, and YI performed some experiments to evaluate differentiation. $\mathrm{Yl}, \mathrm{JT}$, and $\mathrm{CZ}$ performed some experiments on the miRNAs expression analyses. $\mathrm{CD}$ and $\mathrm{DH}$ performed some experiments of animal model construction. TT provided the hybridoma TM- $\beta 1$ cell line. GC and QZ conceived and designed the study, critically revised the manuscript for important intellectual content, and approved the version to be published.

1. Semenza GL. Oxygen sensing, homeostasis, and disease. N Engl J Med 365: 537-547.

2. Semenza GL. Targeting HIF-1 for cancer therapy. Nat Rev Cancer 2003; 3: 721-732.

3. Nicholas SA, Sumbayev VV. The involvement of hypoxia-inducible factor 1 alpha in Toll-like receptor 7/8-mediated inflammatory response. Cell Res 2009; 19: 973-983.

4. Hanahan D, Weinberg RA. Hallmarks of cancer: the next generation. Cell 2011; 144: 646-674.

5. Huang Y, Du KM, Xue ZH, Yan H, Li D, Liu W et al. Cobalt chloride and low oxygen tension trigger differentiation of acute myeloid leukemic cells: possible mediation of hypoxiainducible factor-1alpha. Leukemia 2003; 17: 2065-2073.

6. Kim JS, Cho EW, Chung HW, Kim IG. Effects of Tiron, 4,5-dihydroxy-1,3-benzene disulfonic acid, on human promyelotic $\mathrm{HL}-60$ leukemia cell differentiation and death. Toxicology 2006; 223: 36-45.

7. Liu W, Guo M, Xu YB, Li D, Zhou ZN, Wu YL et al. Induction of tumor arrest and differentiation with prolonged survival by intermittent hypoxia in a mouse model of acute myeloid leukemia. Blood 2006; 107: 698-707.

8. Nguyen-Khac F, Della Valle V, Lopez RG, Ravet E, Mauchauffe M, Friedman AD et al. Functional analyses of the TEL-ARNT fusion protein underscores a role for oxygen tension in hematopoietic cellular differentiation. Oncogene 2006; 25: 4840-4847.

9. Song LP, Zhang J, Wu SF, Huang Y, Zhao Q, Cao JP et al. Hypoxia-inducible factor1alpha-induced differentiation of myeloid leukemic cells is its transcriptional activity independent. Oncogene 2008; 27: 519-527.

10. Ryan BM, Robles Al, Harris CC. Genetic variation in microRNA networks: the implications for cancer research. Nat Rev Cancer 10: 389-402.

11. Taguchi A, Yanagisawa K, Tanaka M, Cao K, Matsuyama Y, Goto H et al. Identification of hypoxia-inducible factor-1 alpha as a novel target for miR-17-92 microRNA cluster. Cancer Res 2008; 68: 5540-5545.
12. Ghosh G, Subramanian IV, Adhikari N, Zhang X, Joshi HP, Basi D et al. Hypoxia-induced microRNA-424 expression in human endothelial cells regulates HIF-alpha isoforms and promotes angiogenesis. J Clin Invest 2010; 120: 4141-4154.

13. Cascio S, D'Andrea A, Ferla R, Surmacz E, Gulotta E, Amodeo V et al. miR-20b modulates VEGF expression by targeting HIF-1 alpha and STAT3 in MCF-7 breast cancer cells. J Cell Physiol 2010; 224: 242-249.

14. Kulshreshtha R, Ferracin M, Wojcik SE, Garzon R, Alder H, Agosto-Perez FJ et al. A microRNA signature of hypoxia. Mol Cell Biol 2007; 27: 1859-1867.

15. Zhao XY, Zhao KW, Jiang Y, Zhao M, Chen GQ. Synergistic Induction of Galectin-1 by CCAAT/Enhancer Binding Protein \{alpha\} and Hypoxia-inducible Factor 1\{alpha\} and its role in differentiation of acute myeloid leukemic cells. J Biol Chem 286: 36808-36819.

16. O'Donnell KA, Wentzel EA, Zeller KI, Dang CV, Mendell JT. c-Myc-regulated microRNAs modulate E2F1 expression. Nature 2005; 435: 839-843.

17. Yang L, Jiang Y, Wu SF, Zhou MY, Wu YL, Chen GQ. CCAAT/enhancer-binding protein alpha antagonizes transcriptional activity of hypoxia-inducible factor 1 alpha with direct protein-protein interaction. Carcinogenesis 2008; 29: 291-298.

18. Liu M, Lee MH, Cohen M, Bommakanti M, Freedman LP. Transcriptional activation of the Cdk inhibitor p21 by vitamin D3 leads to the induced differentiation of the myelomonocytic cell line U937. Genes Dev 1996; 10: 142-153.

19. Sanges D, Cosma MP. Reprogramming cell fate to pluripotency: the decision-making signalling pathways. Int J Dev Biol 54: 1575-1587.

20. Weber-Nordt RM, Mertelsmann R, Finke J. The JAK-STAT pathway: signal transduction involved in proliferation, differentiation and transformation. Leuk Lymphoma 1998; 28: 459-467.

21. Abbas T, Dutta A. p21 in cancer: intricate networks and multiple activities. Nat Rev Cancer 2009; 9: 400-414.

22. Murray PJ. The JAK-STAT signaling pathway: input and output integration. $J$ Immunol 2007; 178: 2623-2629.

23. Tanaka T, Kitamura F, Nagasaka $Y$, Kuida K, Suwa $H$, Miyasaka M. Selective long-term elimination of natural killer cells in vivo by an anti-interleukin 2 receptor beta chain monoclonal antibody in mice. J Exp Med 1993; 178: 1103-1107.

24. Notta F, Mullighan CG, Wang JC, Poeppl A, Doulatov S, Phillips LA et al. Evolution of human BCR-ABL1 lymphoblastic leukaemia-initiating cells. Nature 2011; 469: 362-367.

25. Fontana L, Pelosi E, Greco P, Racanicchi S, Testa U, Liuzzi F et al. MicroRNAs 17-5p-20a106a control monocytopoiesis through AML1 targeting and M-CSF receptor upregulation. Nat Cell Biol 2007; 9: 775-787.

26. Woods $\mathrm{K}$, Thomson JM, Hammond SM. Direct regulation of an oncogenic micro-RNA cluster by E2F transcription factors. J Biol Chem 2007; 282: 2130-2134.

27. Yan HL, Xue G, Mei Q, Wang YZ, Ding FX, Liu MF et al. Repression of the miR-17-92 cluster by $\mathrm{p} 53$ has an important function in hypoxia-induced apoptosis. EMBO J 2009; 28: 2719-2732.

28. YuZ, Wang C, Wang M, Li Z, Casimiro MC, Liu M et al. A cyclin D1/microRNA 17/20 regulatory feedback loop in control of breast cancer cell proliferation. J Cell Biol 2008; 182: 509-517.

29. Matsubara H, Takeuchi T, Nishikawa E, Yanagisawa K, Hayashita Y, Ebi H et al. Apoptosis induction by antisense oligonucleotides against miR-17-5p and miR-20a in lung cancers overexpressing miR-17-92. Oncogene 2007; 26: 6099-6105.

30. Hayashita $\mathrm{Y}$, Osada H, Tatematsu $\mathrm{Y}$, Yamada H, Yanagisawa $\mathrm{K}$, Tomida $\mathrm{S}$ et al. A polycistronic microRNA cluster, miR-17-92, is overexpressed in human lung cancers and enhances cell proliferation. Cancer Res 2005; 65: 9628-9632.

31. He L, Thomson JM, Hemann MT, Hernando-Monge E, Mu D, Goodson $S$ et al. A microRNA polycistron as a potential human oncogene. Nature 2005; 435: 828-833.

32. Volinia S, Calin GA, Liu CG, Ambs S, Cimmino A, Petrocca F et al. A microRNA expression signature of human solid tumors defines cancer gene targets. Proc Natl Acad Sci USA 2006; 103: 2257-2261.

33. Ventura A, Young AG, Winslow MM, Lintault L, Meissner A, Erkeland SJ et al. Targeted deletion reveals essential and overlapping functions of the miR-17 through 92 family of miRNA clusters. Cell 2008; 132: 875-886.

34. Wang L, Arcasoy MO, Watowich SS, Forget BG. Cytokine signals through STAT3 promote expression of granulocyte secondary granule proteins in 32D cells. Exp Hematol 2005; 33: 308-317.

35. Li Z, Yang CS, Nakashima K, Rana TM, Small RNA. mediated regulation of iPS cell generation. EMBO J 30: 823-834.

36. Saito $Y$, Murata-Kamiya N, Hirayama T, Ohba Y, Hatakeyama M. Conversion of Helicobacter pylori CagA from senescence inducer to oncogenic driver through polaritydependent regulation of p21. J Exp Med 207: 2157-2174.

37. Wong P, Iwasaki M, Somervaille TC, Ficara F, Carico C, Arnold C et al. The miR-17-92 microRNA polycistron regulates MLL leukemia stem cell potential by modulating p21 expression. Cancer Res 70: 3833-3842.

38. Foshay KM, Gallicano Gl. miR-17 family miRNAs are expressed during early mammalian development and regulate stem cell differentiation. Dev Biol 2009; 326: 431-443.

39. Zhang M, Liu Q, Mi S, Liang X, Zhang Z, Su X et al. Both miR-17-5p and miR-20a alleviate suppressive potential of myeloid-derived suppressor cells by modulating STAT3 expression. J Immunol 186: 4716-4724.

40. Hevehan DL, Miller WM, Papoutsakis ET. Differential expression and phosphorylation of distinct STAT3 proteins during granulocytic differentiation. Blood 2002; 99: 1627-1637. 